\title{
Correction to: In-Situ Synchrotron X-ray Diffraction Studies on Effects of Plastic and Elastic Loading on bcc Phase Transformations of a 3rd Generation 1 GPa Advanced High Strength Steel
}

\author{
P. EFTEKHARIMILANI, R.M. HUIZENGA, B. KIM, A. BERNASCONI, \\ and M.J.M. HERMANS
}

https://doi.org/10.1007/s11661-017-4453-7

(C) The Minerals, Metals \& Materials Society and ASM International 2017

\section{Correction to:}

Metallurgical and Materials Transactions A,

Volume 49A, January 2018, pp. 78-87

https://doi.org/10.1007/s11661-017-4415-0

IN the original article there is an error in the first sentence of the abstract. bcc-to-bcc should be fcc to bcc. The corrected sentence is as follows:

In this paper, we describe the effects of mechanical loading on fcc to bcc phase transformations of an Advanced High Strength Steel during cooling.

P. EFTEKHARIMILANI, R.M. HUIZENGA, B. KIM, and M.J.M. HERMANS are with the Department of Materials Science and Engineering, Delft University of Technology, Mekelweg 2, 2628 CD Delft, The Netherlands. Contact e-mail: p.eftekharimilani@ tudelft.nl A. BERNASCONI is with the European Synchrotron Radiation Facility, 6 Rue Jules Horowitz, BP 220, 38043 Grenoble Cedex, France.

The original article can be found online at https://doi.org/10.1007/s11661-017-4415-0.

Article published online December 27, 2017 